it helps us to better understand the relationship between age cohorts and hospital treatment for substance use disorders, and provides a rationale for further exploration of the key factors associated with the most efficient care for adult patients with substance use disorders.

$1 \mathrm{Xu} \mathrm{KT}$. Financial disparities in prescription drug use between elderly and nonelderly Americans. Health Aff 2003; 22: 210-1.

2 Ross JS, Bradley EH, Busch SH. Use of health care services by lowerincome and higher-income uninsured adults. JAMA 2006; 295: 202736.

3 Clark RE, Samnaliev M, McGovern MP. Treatment for co-occurring mental and substance use disorders in five state Medicaid programs. Psychiatr Serv 2007; 58: 942-8.

4 Adelmann PK. Mental and substance use disorders among Medicaid recipients: prevalence estimates from two national surveys. Adm Policy Ment Health 2003; 31: 111-29.

Wanqing Zhang is a researcher, University of Nebraska Medical Center, email: wazhang@unmc.edu; Shinobu Watanabe-Galloway is Assistant Professor, University of Nebraska Medical Center, USA.

doi: $10.1192 / \mathrm{pb} .34 .4 .162 \mathrm{a}$

\section{Old age psychiatry and the recovery model}

We fail to see what all the fuss over the 'recovery model' is about. Nor can we appreciate why it has been so powerful in 'influencing mental health service development around the world'. ' Working with older people, especially those with dementia but also those with functional disorders, recovery has been the style of our work long before it became a jargon term.

Our day assessment unit aims to give both the patient and their relatives as much autonomy as possible despite progressive mental disability. Enhancing well-being and giving meaning to people's lives, empowering patients and carers to make decisions collaboratively, and enabling activities salient to the patient and carer have been integral to our work for years. We run in-house educational courses and support groups for carers. Some carers' courses have continued as informal groups who meet and support each other even after the relative they were caring for has died. An upmarket chain coffee emporium offers free drinks for one peer support group organised by a patient with a history of bipolar affective disorder that meets in their café; perhaps some would say this is unwarranted charity: the group does not think so. A 'drop-in' at a local church hall is popular. Carers contribute to our educational programme for staff.

To us, the recovery model represents standard highquality old age psychiatric practice. Often we can see the quality of life of patients and their relatives improve, despite progressive illness and disability, as understanding and coping mechanisms increase. Scientific evidence is not always necessary, especially when it is measured in economic rather than person-centred terms. The recovery model is a humane, self-esteem, self-respect approach, perhaps one which all psychiatry can learn from older people's services. We will not become complacent in our practices even if services for younger people are catching up with us.

1 Warner R. Does the scientific evidence support the recovery model? Psychiatrist 2010; 34: 3-5.
Claire Hilton is Consultant Old Age Psychiatrist, Bentley House Day Assessment Unit, Central and North West London NHS Foundation Trust, 15-27 Headstone Drive, Harrow HA3 5QY, email: claire.hilton@nhs.net; Jo Hulman is Day Services Manager at the same trust.

doi: $10.1192 / p b .34 .4 .163$

\section{Screening test for dementia}

Screening for dementia or early cognitive impairment is of paramount importance. However, it should not be limited to patients in their seventies but should be done even for patients in their nineties. Otherwise we are going to create a biased service. We have to understand that screening for dementia will help with further investigations and treatment of reversible causes of this illness. ${ }^{1}$

Another important issue would be that of mild cognitive impairment which, although not formally classified, has received due attention as interventions at this stage will certainly delay the expression of clinical symptoms. ${ }^{2}$ The National Dementia Strategy ${ }^{3}$ is indeed a step in a right direction. With huge infusion of funds across England and Wales as well as establishing early diagnosis and intervention clinics, it is of paramount importance in identifying probable mild cognitive impairment early on by utilising various screening tests including blood test, scans and battery of neuropsychological testing. This will certainly help both patients and carers to be well prepared and informed, and reduces the risk of early institutionalisation.

Therefore, to say that patients in their nineties do not deserve full investigation is rather a Stone Age statement. Screening tests should be available to everyone regardless.

1 Boustani M, Peterson B, Harris R, Lux LJ, Krasnow C, Sutton SF, et al. Screening for Dementia. Systematic Evidence Review. Agency for Healthcare Research and Quality, 2003 (http://www.ncbi.nlm.nih.gov/ books/bv.fcgi?rid=hstat3.chapter.28271)

2 Callahan CM, Hendrie HC, Tierney WM. Documentation and evaluation of cognitive impairment in elderly primary care patients. Ann Intern Med 1995; 122: 422-9.

3 Department of Health. National Dementia Strategy. Department of Health, 2009.

Sanjay Jain is a locum consultant psychiatrist of old age, Devon NHS Partnership Trust, email: sanjay.jain@nhs.net

doi: $10.1192 / \mathrm{pb} .34 .4 .163 \mathrm{a}$

\section{Religiosity gap in psychiatry}

I thank the authors ${ }^{1}$ for their well-considered and helpful article which argues for more understanding and discussion of people's religious and spiritual beliefs. They make the point that 'Individuals with religious beliefs may be extremely reluctant to engage with psychiatric services that they perceive to be atheistic, scientific and disparaging of religion'. They then cite the example of ultra-Orthodox Hasidic Jews that fear misdiagnosis.

How strange and very unfortunate then that in the very same month, the British Journal of Psychiatry publishes an article that basically diagnoses Ezekiel, a prominent Old Testament Biblical prophet, as having schizophrenia. ${ }^{2}$ All of Ezekiel's experiences are attributed to the illness, thus dismissing the possibility that God actually did communicate 
with him in the ways described. The Old Testament is of course the basic scripture for Orthodox Jews.

No wonder that there is a problem then - the religiosity gap between psychiatrist and patient described by Dein et al is demonstrated in a painfully clear way.

1 Dein S, Cook CCH, Powell A, Eagger S. Religion, spirituality and mental health. Psychiatrist 2010; 34: 63-4.

2 Stein G. The voices that Ezekiel hears - Psychiatry in the Old Testament. Br J Psychiatry 2010; 196: 101

Joss Bray is a substance misuse specialist doctor, Dene Consulting, Alnwick, Northumberland, email: jossbray@aol.com

doi: $10.1192 / \mathrm{pb} .34 .4 .163 \mathrm{~b}$

\section{What's in a name? Patient, survivor, client}

Now here is something the Chancellor's axe could fall upon without pain or loss in his endeavours to alleviate the nation's debts! I am astonished that anyone should spend money - let alone time - on such a futile piece of pseudo research. ${ }^{1}$

What does it tell us? That out of 336 'receivers of mental health services' in east Hertfordshire, the majority, just like their counterparts in London, would rather be called patients or clients than service users or survivors; and that the term patient seems to be more commonly used in dealings with psychiatrists, whereas social workers favour service user. How many times in my 20 years' experience attending my son's ward rounds have I listened to the consultant refer to the patient, while the social services people in the same meeting refer to him as the service user!

But this should come as no surprise. Psychiatrists have been trained as scientists, brought up to identify things and call them by their proper names. Social workers appear to have been trained in a junior branch of social engineering, the offspring of a curious miscegenation between the politics of positive discrimination, which sets out to eliminate anything that might be construed as judgemental or in some sense relegating people to a category of inferiority, and the language of consumerism which emphasises individual freedom of choice and the inalienable right to shop around and find your own bargain.

Language is there to be manipulated. A couple of years ago the CEO of my local mental health trust stopped referring to 'your son's illness' in correspondence and began to speak of his 'recovery journey'. When I suggested that did not seem terribly appropriate where schizophrenia was concerned she referred me to the website of the Social Care Institute for Excellence where I learnt that 'In ordinary speech, recovery is often (sic!) equated with cure', but that of course is an outmoded way of looking at the matter when severe mental illness is concerned; in effect, if you think you have recovered, then you have.

But has anyone stopped to consider why patient might be construed as excluding anyone, as being in any way derogatory or demeaning when applied to those 'receiving mental health services'? Cancer patients do not seem to find it so. Nor, as far as I am aware, do they consider themselves to be 'receiving services'. They are not well and they go to the doctor in the hope that he (forgive me, but this is a gender non-specific pronoun when used in this sense in English) will make them better.

The crucial definition of a patient is one who suffers, who endures an illness, who is acted upon rather than acts. Most of us, on the basis of modern advances in science and of several decades of pretty successful practice, are happy to go to a doctor trusting in his knowledge and in his commitment to making us better rather than, say, exploiting us as potential sources of income.

Client signifies a very different kind of relationship. Who in normal life has clients? Solicitors, management consultants, call girls, architects. Although it is sometimes used merely as a posh word for customer, the essential difference seems to be that a client is buying a service and himself defines what he wants. The provider of the service seeks to keep his client happy by giving him what he wants, even if it means doing a little creative accounting or throwing in a lunch in an expensive restaurant. The client is the one who calls the shots. Not, surely, the kind of thing one expects of the relationship between someone who is not well and his healer.

Tinkering with terminology may amount to little more than a foolish waste of public money if we are talking about people a little bruised by life. If it distracts from providing proper treatment and care for people who are seriously ill, then it begins to look rather like Nero's fiddling as Rome burned.

1 Simmons P, Hawley CJ, Gale TM, Sivakumaran T. Service user, patient, client or survivor: describing recipients of mental health services. Psychiatrist 2010; 34: 20-3.

Tim Salmon, writer, London, email: pb@rcpsych.ac.uk

doi: $10.1192 / p b .34 .4 .164$ 